Revista Iberoamericana, Vol. LXX, Núms. 208-209, Julio-Diciembre 2004, 749-772

\title{
REVISTAS, INTELECTUALES Y FORMACIONES CULTURALES IZQUIERDISTAS EN LA ARGENTINA DE LOS VEINTE
}

\author{
POR \\ HORACIO TARCUS \\ Universidad de Buenos Aires \\ Universidad de La Plata
}

Un intenso proceso de efervescencia social, política y cultural se inicia con los ecos locales de la revolución rusa, el estallido y expansión de la Reforma Universitaria (1918) y las grandes huelgas obreras de los años 1918-1919, cerrándose el ciclo con el golpe militar de setiembre de 1930. Esta “década larga”, tradicionalmente abordada como el período del enfrentamiento entre las revistas de la izquierda comprometidas con el realismo artístico, por un lado, y las revistas de la vanguardia artística, por otro, fue fecunda en la proliferación de formaciones culturales y en publicaciones que abarcan en verdad un espectro político-intelectual mucho más amplio, complejo e intrincado que el que permite pensar la contraposición Florida-Boedo. Incluso admitiendo que la oposición realismo-vanguardias funcionó como una divisoria de aguas en el período, dicho par antinómico no se corresponde puntualmente con una confrontación izquierdas/derechas. Los “casos” de Roberto Arlt y de Raúl González Tuñón, en tanto descentrados de dicho esquema, en cuanto exceden la mera antinomia, se han convertido en paradigmáticos. ${ }^{1}$ Como se ha señalado, "las fracciones juveniles del campo político se superponían a menudo con las del campo intelectual, intercambiando aliados y protagonistas. El movimiento de renovación estética no había cristalizado aún en posiciones ideológicas irreductibles... Existe un continuum ideológico-experiencial animado por el proyecto de conquistar a la sociedad, y cambiarla estética, moral o políticamente” (Sarlo, Una modernidad periférica 111).

Y si bien la crítica ha avanzado en este sentido, proponiendo nuevas miradas sobre los escritores y las revistas centrales del período (Proa y Martín Fierro, La Campana de Palo y Claridad), una aproximación a otras figuras intelectuales y otras formaciones culturales del período menos transitadas -aquellas reunidas en torno a revistas como Insurrexit (1920-21), Cuasimodo (1920-1921), Revista de Oriente (1925-1926), Babel (1921-1928) y La Vida Literaria (1928-1932)-, acaso aporte a la configuración de un escenario más complejo para la comprensión del período, desde el cual podrá apreciarse, por ejemplo, cómo muchos de los jóvenes habitualmente adscriptos al "vanguardismo

\footnotetext{
${ }^{1}$ Sobre los alcances y límites de la oposición Florida/Boedo, véase, fundamentalmente, Prieto 1969, y Sarlo 1983 y 1988. Es útil consultar también los numerosos testimonios de los memorialistas (Barletta, Yunque, R. González Tuñón, Córdova Iturburu, González Lanuza, Girondo, entre los principales).
} 
artístico puro” y al “apoliticismo” de Florida -como Jorge Luis Borges, Eduardo González Lanuza y Francisco Piñero-emergieron en el campo intelectual como escritores anarquistas atraídos por la revolución rusa; al mismo tiempo que muchas formaciones izquierdistas -diez años antes de que el stalinismo impusiera como canon el realismo socialista- buscaron articular vanguardia política con vanguardia artística. Asimismo, podrá apreciarse cómo una figura intensamente receptiva de las vanguardias europeas, José Carlos Mariátegui, fue ampliamente difundido en las revistas argentinas de los veinte. Y cómo incluso en la prehistoria de Sur, la revista más característica de la élite liberal, aparecen comprometidas corrientes de pensamiento como el americanismo, el antiimperialismo y el socialismo. Veremos cómo el peruano Mariátegui, el argentino Samuel Glusberg y el norteamericano Waldo Frank concibieron inicialmente una revista americanista de proyección continental-que iba a llamarse Nuestra América-, aunque por curiosas vicisitudes, el proyecto quedó en manos de Victoria Ocampo, quien lo lanzará con su propia orientación en 1931, ya rebautizado con su nombre definitivo.

I

"INSURREXIT": DEL ANARQUISMO AL MARXISMO LIBERTARIO

El Grupo Insurrexit, hasta hoy apenas una confusa mención en los libros de historia del movimiento estudiantil, pertenece más al orden del mito que al de la historia. Sin embargo, a juzgar por las referencias que encontramos en fuentes de la época, así como por las personalidades que pasaron por las páginas de su revista, puede inferirse que no pasó inadvertido a sus contemporáneos. Incluso su nombre fue retomado por otro grupo, más de una década después, homenaje que, por otra parte, contribuyó a hacer todavía más confusa la historia. No faltan quienes confunden el primer Insurrexit (1920-1921), un emprendimiento independiente, de cuño marxista libertario, con el segundo Insurrexit (1933-1935), que editó un periódico del mismo nombre, inspirado por Héctor P. Agosti y que fue vocero de los universitarios comunistas (y sus compañeros de ruta), por donde hizo su paso el joven Ernesto Sábato. ${ }^{2}$ Es que no es sencillo disipar las brumas que se ciernen sobre Insurrexit. Primer y principal obstáculo: todavía no ha podido reconstruirse una colección completa de su revista. Segundo: ninguno de sus mentores vive ya y para peor, algunos de los que vivieron hasta hace unos pocos años, no querían recordar el radicalismo de su juventud. ${ }^{3}$

${ }^{2}$ El trabajo más documentado de historia del movimiento estudiantil en la Argentina de A. Ciria y $\mathrm{H}$. Sanguinetti, menciona brevemente al grupo Insurrexit, reconociendo que la bibliografía al respecto "es escasa". Pero atribuye al primer Insurrexit figuras del segundo (como Angel Hurtado de Mendoza y Paulino González Alberdi).

${ }^{3}$ En los años setenta, el poeta y crítico Eduardo González Lanuza, por entonces colaborador habitual de Sur y La Nación, se negó rotundamente a recordar esa experiencia ante los requerimientos de Emilio Corbière. Poca gracia le habrá causado el soneto recordatorio de Enrique Espinoza (seud. Samuel Glusberg): “En el año veintitantos tus donaires/ primeros conocí en la extrema izquierda./ ¿Quién del grupo Insurrexit hoy se acuerda/ dentro y fuera de nuestro Buenos Aires?[...] Tú, González Lanuza en Sur ahora,/por Gandhi a lo pacífico inclinado,/el insurrecto no eres ya de otrora...”. (20). 
En junio de 1918 emergía en Córdoba la Reforma Universitaria. A escasos seis meses, había estallado la revolución socialista en Rusia y su onda se expandía al resto de Europa. La fracción internacionalista del Partido Socialista iba a fundar el Partido Socialista Internacional, que poco después iba a llamarse Partido Comunista de la Argentina. Entre los intelectuales radicalizados, emerge la figura de José Ingenieros, respaldando a los jóvenes reformistas y señalándoles el camino abierto por los “maximalistas rusos”. Entre los sectores izquierdistas del estudiantado surge un fermento libertario, donde caben y se entrecruzan Reforma Universitaria y revolución social, clasismo y juvenilismo, socialismo y antiimperialismo, cientificismo y romanticismo, Lenin y Kropotkin, Henri Barbusse y Almafuerte, Ingenieros y Lugones. Insurrexit, vocero del ala más declaradamente izquierdista de la Reforma Universitaria, está animada por este espíritu, propio de fines de la década del diez y principios de la del veinte. (A fines de esta década, dicho universo habrá estallado: el reformismo universitario, incapaz de darse una expresión política, sufrirá un importante retroceso; el amplio arco de apoyo a la experiencia soviética, por su parte, se encorsetará cada vez más dentro del "marxismo-leninismo", quedando fuera desde entonces la vocación romántica y los anhelos libertarios.)

El primer número de Insurrexit. Revista Universitaria apareció el 8 de setiembre de 1920. Según su editorial, el nombre viene del latín, insurgo, y su sonoridad sugiere a sus editores "la presencia de una rebeldía reflexiva, seria, decisiva", donde "palpita la impaciencia” y estalla la pasión. En la primera página, el rosarino Francisco Piñero, estudiante de abogacía, cuestiona "el viejo derecho". Una encuesta interroga a Leopoldo Lugones y a Alfredo Palacios. Unas páginas después, Carlos Lamberti, estudiante de medicina, presenta unas nociones elementales de la teoría marxista, mientras la siguiente reproduce breves frases de Rafael Barret y de Kropotkin. Eduardo González Lanuza publicó allí los sonetos de los que no querría acordarse medio siglo después: "Sé optimista ante el pájaro que canta/[...]/Y ante el triunfo de las alboradas/ porque a despecho de los Torquemadas/ La verdad se abre paso por el mundo" (11). Breves recuadros buscan interpelar la conciencia social de los jóvenes: "Estudiante: usted va a formar el mundo del mañana. Lea las nuevas teorías sociales y medite. ¡Medite!” (9).

El espíritu de la revista se mueve entre el comunismo anárquico y el marxismo libertario donde cabe, incluso, un leninismo leído en clave libertaria, antiparlamentarista y consejista. Recordemos que, especialmente en sus primeros años, la experiencia soviética atrajo la atención de muchas corrientes anarquistas. El compromiso crítico de los anarquistas con la Unión Soviética concluye en 1921 (año del aplastamiento del movimiento machnovista y de la represión a la insurrección de Kronstadt), pero importantes núcleos libertarios en todo el mundo siguen con expectación la experiencia del país de los soviets, e incluso otros -los “anarco-bolcheviques”- continúan apoyándola de modo entusiasta (Doeswijk). Los jóvenes del Grupo Insurrexit se mueven dentro de este espectro, sin adherir por el momento al recién creado Partido Comunista, pero con vínculos con los "terceristas" del Partido Socialista: el ala izquierda, pro Tercera Internacional, que lideró Enrique del Valle Iberlucea. El socialista Juan Antonio Solari, “tercerista” por breve tiempo, colaborará estrechamente con Insurrexit.

Aunque atraídos inicialmente por el espíritu libertario, los jóvenes no tienen vínculos orgánicos con el anarquismo doctrinario, e incluso publican una autocrítica del anarquista 
norteamericano Robert Minor, "Mi opinión ha variado" ( $n^{\circ}$ 4, 5 y 6), que llama a comprender mejor y a apoyar a la Rusia de los Soviets. Su referente internacional es un nucleamiento intelectual, el Grupo Clarté (Claridad), que desde París inspiran los escritores Henri Barbusse y Romain Rolland, y cuyo lema es: "Hagamos la revolución previamente en los espíritus". Dentro del campo intelectual local, Insurrexit mantiene relaciones fraternales con Cuasimodo, la revista que dirige el intelectual "anarcobolchevique” Julio R. Barcos, y, del otro lado de la cordillera, con Juventud, el órgano de la Federación de Estudiantes de Chile.

Insurrexit informa y fija posición ante los conflictos estudiantiles, aunque su "misión” parece dictada por la necesidad de comprometer a la juventud con la "cuestión social”, de promover la "unidad obrero-estudiantil”: “¿Qué es cada uno de ustedes? Vamos a ver. Un traje entallado, un zapato Walk-Over, una corbata, otras chucherías... Todo a cargo de papá o mamá. [...] Compañeros universitarios, que hacen caso al vigilante y a la historia, 'liguistas', nacionalistas, futuros médicos, abogados, ingenieros, filósofos, aspirantes a oficiales de reserva, dirigentes futuros, escuchen, al abrirse de nuevo las facultades, nuestra palabra: ¡Viva la revolución rusa! ¡Viva la revolución social! ¡Viva el comunismo!” (“La Universidad” 1). Interpelaciones semejantes a los estudiantes dirigen en sucesivos números Hipólito Etchebehere, Nicolás Olivari, Carlos Machiavello, Francisco Piñero y Julio R. Barcos. Otros temas recurrentes de la revista son las realizaciones sociales de la URSS; la literatura social (Barbusse y Rolland, Almafuerte y Barret) y, finalmente, la situación social y política argentina (Leónidas Barletta propone una central sindical única, una nota anónima informa sobre el congreso socialista "tercerista”, otra sobre la celebración del $1^{\circ}$ de Mayo).

En el $n^{\circ} 4$, la estudiante de odontología Mica Feldman cuestiona doblemente la política de las sufragistas: en primer lugar, porque no han comprendido que mientras no haya revolución social no habrá emancipación de la mujer; y en segundo lugar, porque los derechos políticos, el voto y el parlamento no conducen a la emancipación anunciada: "Buena muestra es la política masculina para tratar de formar partidos políticos femeninos" ("Nuetro voto" 1), argumenta la joven de 18 años. Hipólito Etchebehere, estudiante de ingeniería, escribe en casi todos los números: contra la guerra $\left(n^{\circ} 1\right)$, por la extensión de la revolución rusa ( $n^{\circ} 3$ y 4), sobre "La certeza del triunfo": pasando revista de la crisis social y política en Europa, concluye: "La situación revolucionaria existe en todas partes. La Revolución Social llega. Es más, está realizada ya en Rusia. En eso se basa nuestra fe inquebrantable, racional” (9: 5).

Estos jóvenes universitarios parecen haberse atraído la simpatía de algunas figuras de la generación anterior. Hemos dicho que Lugones y Palacios responden a su encuesta. Además, muchos escritores ceden sus originales o incluso escriben expresamente a pedido de los jóvenes: Arturo Capdevila publica allí “La tierra”, una crítica de la propiedad privada; Alfonsina Storni no sólo colabora con sus versos, sino que ensaya una reflexión política “En la encrucijada” de la civilización moderna ( $\left.n^{\circ} 4\right)$; Herminia Brumana anticipa una serie de relatos (“Chafalonías”, $\mathrm{n}^{\circ}$ 7) y Horacio Quiroga envía dos colaboraciones, una de ellas un alegato antibelicista ("La propaganda post-guerra”, $n^{\circ} 9$ ). En el $n^{\circ} 7$ se da a conocer también una carta que les dirige desde Francia el mismísimo Barbusse: "Mis compañeros de París, de otras partes y yo, estamos, absolutamente, de corazón y de espíritu con ustedes”. 


\section{EL GRUPO INSURREXIT}

Si poco se sabe de la revista, más misterioso aún es el colectivo editor, autodefinido: “Grupo Universitario Insurrexit, comunista antiparlamentario”. Fiel a su programa, la revista no tiene director. Un aviso advierte: "Se responsabilizan absolutamente de ella, cada uno y todos los del grupo”. Hoy es posible conocer la estructura del grupo siguiendo los avatares de la vida de dos sus líderes, Hipólito Etchebehere y su compañera. Micaela Feldman había nacido en 1902 en Moisesville, Santa Fe. Sus padres, rusos judíos, llegaron a la Argentina huyendo de los pogroms algún tiempo antes de su nacimiento. Años más tarde, mientras cursa en el colegio nacional de Rosario, aparece adherida a un grupo anarquista y luego integra la Agrupación Femenina “Luisa Michel” (Maitron; Doeswijk). Pero en 1920 se instala en Buenos Aires para cursar la carrera de Odontología y es entonces cuando se liga al grupo Insurrexit. Un extraordinario testimonio inédito de Mica (que en Europa comenzará a firmar Mika) Felman a un corresponsal argentino nos permite hoy vertebrar toda esta historia.

Estamos en setiembre de 1920. Dos rosarinos como yo, Francisco Rinesi y Francisco Piñero, que conocen mis ideas por haberlas yo manifestado siendo estudiante en el colegio nacional, vienen a verme para informarme de la fundación de Insurrexit y pedir mi adhesión. Por ser ambos hijos de familias burguesas, no di crédito inmediato a la seriedad de la empresa, reservando mi respuesta hasta saber mejor las finalidades del grupo. Al cabo de una semana volvieron los dos jóvenes en compañía de Hipólito Etchebehere, cuya imagen, ese día, nunca se me borró de la memoria. Alto, delgado, de tez muy clara, ojos de un raro color gris azulado que le iluminaban extrañamente el rostro, llevaba un chamberguito de alas redondeadas vueltas hacia arriba, plantado en mitad de la cabeza como una aureola. Habló largo rato, sin énfasis, exponiendo sus ideas con una claridad ejemplar, una fuerza y una convicción que hacían difícil no creer en lo que él creía. Jamás he vuelto a ver en la vida un ser tan luminoso. Y no me ciega el amor que nos unió durante dieciséis años, hasta la hora de su muerte. Todos aquellos que lo conocieron dicen como yo. (Etchebehere 4)

Hipólito Etchebehere había nacido con el siglo en Sa Pereira, Provincia de Santa Fe, de padres franceses. Instalado con su familia en Buenos Aires, aún no tiene 19 años cuando desde el balcón de su casa asiste estremecido al pogromo que la policía y las bandas nacionalistas de la Liga Patriótica desatan en el humilde barrio judío del “Once”. Era uno de los momentos cruciales de lo que quedó en la historia argentina como la "semana trágica” de enero de 1919. Según el testimonio de Mica, esta experiencia lo marcará para toda su vida.

En los días que siguieron a la "semana trágica" escribió afiebradamente un folleto dedicado a los vigilantes, que tenía por título "Escucha la verdad" y lo fue repartiendo a los policías que hacían guardia en las calles. Pocas horas después estaba en la cárcel por delito contra la seguridad del Estado. Por ser hijo de una familia bien considerada, tuvo el honor de escuchar los consejos del jefe de policía y la suerte de no ser mandado al presidio de Usuhaia. Cuando salió en libertad abandonó la casa familiar para no comprometer más a los suyos. Comienza entonces para él una vida difícil. Dura poco en 


\begin{abstract}
los talleres donde entra a trabajar, a causa de la propaganda revolucionaria que difunde entre los obreros. Vive en altillos prestados, come algunas veces en casa de su madre, otras veces no come. Consigue dos o tres lecciones particulares que ni siquiera sabe hacerse pagar, pasa largas horas en la biblioteca del Partido Socialista leyendo a Kropotkine, Proudhon, la Historia de la Comuna de París por Lissagaray, con el afán de adquirir los elementos teóricos que habrán de cimentar su fe de revolucionario, buscando al mismo tiempo voluntarios para iniciar una acción colectiva. (1-3)
\end{abstract}

El grupo se reúne en asamblea todos los sábados por la noche en el local de la Federación de Empleados de Comercio, en Suipacha 74 de la Ciudad de Buenos Aires. Suelen participar, además de los redactores de la revista ya citados, el lingüista Angel Rosenblat y el joven peruano Víctor Raúl Haya de la Torre, exiliado entonces en Buenos Aires. La revista es financiada a través de la actividad del grupo, con la ayuda de la directora de escuela Carolina Gómez Cabrera, tía de Piñero. En las reuniones se debaten cuestiones políticas, se planifica la revista y se organizan charlas y cursos para dictar en ateneos y sindicatos. Las principales demandas provienen de los anarquistas. Sin embargo, recuerda Mika: "La revolución rusa, catalizadora de rebeldías, nos planteaba la necesidad de abordar el marxismo” (5). Es así que los días domingo un grupo de lectura vuelve a reunirse en Suipacha 74, ahora para leer colectivamente El origen de la familia de Federico Engels.

El grupo se disuelve hacia 1921. Si bien una parte perseverará en la experiencia colectiva revolucionaria, algunos tomarán otros caminos. Bulnes y Rinesi harán carreras exitosas en el Derecho y llegarán a jueces. Juan Antonio Solari no tardará en volver al PS, del que será dirigente, mientras su mujer, la maestra y narradora Herminia Brumana, permanecerá fiel al ideario anarquista; el dramaturgo y periodista Leónidas Barletta será durante décadas compañero de ruta del comunismo; Angel Rosenblat, un lingüista de renombre continental. Pero parte del grupo sigue el derrotero izquierdista radical: en 1924 Hipólito Etchebehere, Mica Feldman, Alberto Astudillo, Héctor Raurich y José Paniale ingresarán al PC. La experiencia será breve: formarán la primera fracción izquierdista que después de romper filas con el comunismo, fundará el Partido Comunista Obrero y editará el periódico La chispa (1926-1929). Los “chispistas” Raurich y Paniale animarán las formaciones políticas y culturales trotskistas de los años treinta. Hipólito Etchebehere y su compañera Mica Feldman se verán llevados por los vientos de la revolución y contrarrevolución mundiales: Berlín en 1932, hasta el ascenso de Hitler; París entre 1933 y 1935, en los prolegómenos del Frente Popular; Madrid en 1936, con el estallido de la guerra civil española. Él encontró la muerte en el frente, en Sigüenza, combatiendo en la columna del POUM. Mica permaneció en el frente hasta terminada la guerra, alcanzando el grado de capitana, y en 1939 logró escapar a París. Murió en esa ciudad, nonagenaria, a mediados de 1992.

Finalmente, Eduardo González Lanuza y Pancho Piñero se orientarán hacia la literatura de vanguardia, en un movimiento de convergencia con Jorge Luis Borges. El joven Borges, poeta anarquizante, regresa a Buenos Aires a principios de 1921 y trae con él el ultraísmo. Meses después publicará en Cuasimodo, la revista hermana de Insurrexit, sus poemas “Rusia” y “Guardia roja”-avances de Los salmos Rojos, el libro que no llegará a ser. 
CUASIMODO: REVOLUCIÓN Y VANGUARDIA ARTÍSTICA

Cuasimodo. Revista decenal apareció en Buenos Aires entre abril y diciembre de 1921. Retomaba el nombre de una primera Cuasimodo que había salido el año anterior en Panamá, dirigida por el anarquista puertorriqueño Nemesio Canale. Instalado éste por un tiempo en Buenos Aires, relanzará el proyecto asociado con el pedagogo anarquista Julio R. Barcos (Coronda, Prov. de Santa Fe, 1883-Buenos Aires, 1960), ampliamente conocido por sus obras de inspiración libertaria, especialmente La libertad sexual de las mujeres y Cómo educa el Estado a tus hijos.

El nombre de la revista aludía al personaje de Nuestra señora de París, de Víctor Hugo, y según F. Ricard, comentarista de una publicación amiga, simbolizaba la monstruosidad "exterior” del pueblo sometido a las exigencias del trabajo físico, pero que tenía un correlato interior en la "belleza moral, con nuestros sueños redentores, con el ideal de nuestros espíritus; yo y mis compañeros del pueblo, los trabajadores manuales, somos los 'Cuasimodos' de esta hora, enamorados de la belleza de una sociedad sin tiranos ni explotadores" ("Voces amigas” 24). El propio Barcos señalaba en el primer número de la edición argentina, cómo la revolución rusa había recolocado a los anarquistas, al menos a la franja de los “anarcobolcheviques": "Hasta ayer los hombres de prédica libertaria en Sud América no hemos sido otra cosa que literatos de la revolución social. Iniciada ésta en el mundo con la República Comunista de Rusia, nos toca a los que hemos sido sinceros en la prédica, transformarnos ahora en soldados para la acción” (“Entre los míos” 10-11). Sin embargo, su adhesión a la edificación del comunismo soviético no implicaba adhesión incondicional a la política de la Internacional Comunista, pues el anarquismo de Cuasimodo se mantenía intransigentemente "antipolítico” y “antiparlamentario”.

La revista se ocupaba de la Rusia de los Soviets y la Europa de la posguerra; de cuestiones educativas y de la defensa de la reforma universitaria; de la situación política de América Latina y de la condición de la mujer; así como de las nuevas teorías sociales, en un arco que iba de Lloyd George a Mahatma Gandhi, pasando por Lenin. Hermana mayor de Insurrexit, comparte con ésta algunas firmas (Eduardo González Lanuza, Juan A. Solari, Herminia Brumana), pero cuenta con colaboraciones originales, figuras como el pedagogo Saúl Taborda, el joven filósofo Carlos Astrada, el médico anarquista Juan Lazarte, el neurocirujano Lelio Zeno, el futuro líder del grupo de Boedo, Elías Casteolnuovo, el narrador realista Álvaro Yunque, y los jóvenes ultraístas liderados por Jorge Luis Borges.

Si bien la vanguardia política sigue nutriendo sus gustos literarios en la literatura realista decimonónica o en el modernismo latinoamericano, asistimos a la emergencia de cruces significativos entre las vanguardias artísticas y las políticas. En ese sentido, E. González Somoza (¿Eduardo González Lanuza?) hace en Cuasimodo el elogio de las vanguardias, de Picasso y de Marinetti en un ensayo “Sobre el futurismo” (abril 1921); en el $n^{\circ} 19$ (junio 1921) se publica una traducción del norteamericano Horace Brodzky en que define al artista como un anarquista en rebeldía contra la tradición; un autor anónimo profetiza "Un arte nuevo para la Rusia sovietista”, donde serán borrados "los límites entre el artista y el público, entre la escena y el espectador...” (octubre 1921). Los editores, además, lanzan acerbas críticas a las figuras de la cultura oficial, sea el neoclasicismo 
artificial de Enrique Larreta o al nacionalismo belicista de Leopoldo Lugones. En este clima, la colaboración de Borges en Cuasimodo no es, pues, casual.

PRISMA, UNA VANGUARDIA ANTIMODERNISTA Y ANTIMERCANTIL

En ese mismo sentido, Eduardo González Lanuza lanzará Prisma, la primera revista mural argentina. Borges recordaba la experiencia de esta revista, cuando en 1921, acompañado por González Lanuza, Francisco Piñero y su primo Guillermo Juan, salían de noche "cargados con baldes de engrudo y escaleras proporcionados por mi madre y caminábamos kilómetros, pegando las hojas a lo largo de Santa Fe, Callao, Entre Ríos y México” "“Las memorias de...” XIII-XIV). Al año siguiente, y con el aporte de Macedonio Fernández, amigo del padre de Borges, el grupo editará la revista Proa. “Aquellos fueron años felices, rememorará Borges, porque en ellos se sumaron las amistades. Son los años de Norah Lange, Macedonio Fernández, Piñero y mi padre. Detrás de nuestro trabajo había sinceridad; sentíamos que estábamos renovando la prosa y la poesía” (XIII-XIV).

Mucho se ha hablado del grupo de noveles escritores ultraístas, del joven Borges y de Macedonio, pero, curiosamente, poco o nada sabemos de Francisco Piñero, a quien el autor de Fervor de Buenos Aires incluía entre los más entrañables de los “años felices”. El olvido puede atribuirse a la temprana muerte y a la escasa obra dejada por el joven poeta, pero es probable que haya operado también algún filtro político: Piñero, al igual que el joven Borges, no sólo estaba comprometido con la poética ultraísta: era un escritor anarquista esperanzado por el experimento soviético. Francisco M. Piñero había nacido en Rosario en 1901, en el seno de una familia tradicional. En 1920 lo encontramos estudiando en la Facultad de Derecho de la Universidad de Buenos Aires y formando parte de Insurrexit. En 1921-1922 forma parte del grupo Prisma y al año siguiente del de la revista Proa.

González Lanuza, apoyado por Borges y Piñero, lanzará, pues, Prisma, donde confluyen pensamiento libertario y poética vanguardista. En el primer cartel (diciembre 1921), además de los poemas ultraístas, una “Proclama” arremetía contra la mercantilización del arte y la "nadería” de la poética modernista atiborrada de cisnes, jardines y dioses griegos. En el segundo cartel (marzo 1922), se agrega la firma de Piñero, con su poema “Tormentas”. El editorial retoma el tenor de la "Proclama” inicial: "Hastiados de los que no contentos con vender, han llegado a alquilar su emoción i su arte, prestamistas de la belleza, de los que estrujan la mísera idea cazada por casualidad, tal vez arrebatada, nosotros, millonarios de vida y de ideas, salimos a regalarlas en las esquinas, a despilfarrar las abundancias de nuestra juventud, desoyendo las voces de los avaros de su miseria”. Y enseguida vendrá la consolidación del movimiento ultraísta en los tres números de Proa (1922-1923), que reunirá otra vez a Borges, Lanuza y Piñero, sumando ahora a Macedonio Fernández.

Pero Francisco Piñero (1901-1923), revolucionario y ultraísta, morirá a los 22 años en un accidente de tránsito. En el prólogo al libro en que sus amigos de la vanguardia política reunirán sus textos, Cerca de los hombres (1923), se informa que "cuando le ocurrió el accidente que le costó la vida en Río Negro, quisieron llevarlo al único hospital confortable de Viedma. Pero ese hospital pertenecía a una congregación religiosa. Se negó 
a que lo condujera allí. Indicó la Asistencia Pública. Luego, en otro pobre hospital de Patagones, murió” (6).

Por su parte, su amigo de la vanguardia artística, Borges, lo recordará en el último número de Proa: "De golpe, con la injuriosa precisión de una afrenta, ha desalmado nuestro fervor el fallecimiento de Francisco Piñero, excelente poeta, mayor amigo y máximo alentador de aventuras intelectuales... Fenecido a los veintidós años, Piñero deja una breve y honda obra crítica, 'La Estética de los Diferentes', y recorriendo por siempre nuestra memoria, una marcha de versos altaneros, definitivos como estatuas" ("Francisco Piñero”, Textos recobrados 173). Tres años después incluirá algunos de sus poemas en el Índice de la nueva poesía americana, junto a los mejores poetas de su generación. Los editores (Borges, Alberto Hidalgo y Vicente Huidobro) abrían la sección consagrada a cada autor con una dirección postal a donde dirigirse. Seguramente fue Borges el que estampó en la página con que se abrían los poemas de su amigo: "Francisco M. Piñero. Se puede escribirle al cielo” (227).

Entre la Vanguardia y el ReAlismo Ruso: la REVISTA DE ORIENTE

A mediados de la década, el fervor entusiasta por la revolución como novedad absoluta cede su lugar a un esfuerzo más sereno por comprender los complejos caminos de la construcción del socialismo en la URSS, a una acción más realista y pragmática por contribuir a romper el aislamiento del Estado Soviético. El clasismo inicial se complejiza con una perspectiva antiimperialista. Es el camino que va de Cuasimodo e Insurrexit hasta la Revista de Oriente.

Ya vimos cómo algunos de los jóvenes “insurrexistas” ingresarán (por breve tiempo) al Partido Comunista. El PC, además de su órgano oficial, La Internacional, edita (o promueve la edición) de publicaciones oficiales u oficiosas, particularmente las "Ediciones La Internacional”, que publica los primeros folletos de Lenin y Trotsky editados en el país, o los Documentos del Progreso (1919-1921), cuadernos quincenales que a pesar de su nombre algo antiguo para el momento (en tanto sugiere una orientación “librepensadora”), difunden la intensa producción de los bolcheviques rusos.

Al mismo tiempo, muchos intelectuales de extracción libertaria se mantienen políticamente independientes respecto del PC local, pero apoyan activamente la causa de la Unión Soviética. Están entre los estudiantes, escritores y obreros a quienes los comunistas acuden para promover distintos comités a lo largo de la década: el "Comité de Ayuda a los Hambrientos Rusos" (como consecuencia del bloqueo internacional y de la sequía del río Volga) y el “Comité de Ayuda a los Estudiantes Rusos Víctimas del Hambre” de 1923, el que, pasado el problema del hambre, se transformó en "Comité de Ayuda Obrera”. Finalmente, hacia 1925 se crea la “Asociación Amigos de Rusia”, que entre sus múltiples actividades editó la Revista de Oriente (1925-1926).

“Oriente” es, para los editores, Rusia, China, India, Marruecos y, por extensión, América Latina; esto es, un símbolo de los pueblos-naciones oprimidos en contraposición al "Occidente” imperialista. La perspectiva revolucionaria aparece articulada aquí con una dimensión nacional-antiimperialista. Leemos en “Propósitos”, editorial del primer número: 
La última guerra europea ha acelerado el despertar de una nueva conciencia humana. Una tragedia tan inmensa no podía resultar estéril. Por encima de los escombros de la guerra, Rusia encarna hoy el anhelo universal de realizar una humanidad nueva y, por eso, frente a la política imperialista de Occidente representada por los Estados Unidos, es para nosotros el símbolo de una nueva civilización. Queremos recoger en nuestras hojas el esfuerzo que a la par de Rusia, se realiza en Méjico, Marruecos, China, la India y desde el fondo de las masas obreras y campesinas de todo el mundo para divulgar entre los obreros e intelectuales de nuestro país y de toda la América del Sud. (1 junio 1925)

Aunque no figura director ni comité editorial, de los sucesivos números se desprende que el equipo permanente de redactores está compuesto por el periodista Oscar Montenegro Paz, el traductor y difusor del pensamiento socialista Marcelo Punyet Alberti y el ahora arquitecto Alberto Astudillo, que proviene de Insurrexit; y que el alma mater de la revista, así como de la Asociación Amigos de Rusia, es el abogado Arturo Orzábal Quintana. Antiimperialista a mediados de la década -en 1925 es uno de los firmantes del manifiesto fundacional de la Unión Latinoamericana, que lidera José Ingenieros- y nacionalista de izquierdas a fines de la misma y en los treinta -cuando funda la "Alianza Continental para la nacionalización del petróleo argentino”, desde la cual apoya la gestión del Gral. Enrique Mosconi al frente de Yacimientos Petrolíferos Fiscales-, Orzábal Quintana despliega durante años una intensa campaña a favor del reconocimiento por parte de la Argentina al gobierno de los Soviets y de fomento del intercambio comercial y cultural entre ambos países. Incluso visita la URSS en 1927, pero a pesar de su pública adhesión al proceso de edificación de la URSS no se afilia al PC. Más que un intelectual-político interesado en las tácticas y estrategias de la revolución, es una suerte de intelectual-diplomático, comprometido en mostrar tanto a la sociedad como al Estado argentinos la conveniencia de aprender de la experiencia soviética y de establecer vínculos con ella.

Los objetivos de la Asociación, repetidos en cada número de la revista, son claros al respecto: " $1{ }^{\circ}$ Propagar en el ambiente intelectual y obrero del país la obra constructiva que se opera en la Rusia Soviética en el terreno político, económico y cultural; $2^{\circ}$ Luchar por el reconocimiento del gobierno ruso y la iniciación de las relaciones comerciales con Rusia; $3^{\circ}$ Propender a un acercamiento entre los círculos obreros e intelectuales del país y los de Rusia; $4^{\circ}$ Analizar el espíritu de post-guerra y el estado político y social de los países triunfantes en la última contienda; $5^{\circ}$ Solidarizarse y ayudar económicamente al estudiante de cualquier parte del mundo que en sus luchas necesite de nuestra ayuda”.

La Asociación, además de editar la revista, dictará conferencias sobre la situación internacional y los logros de la edificación de la URSS y creará una biblioteca de autores rusos, formada sobre la base de intercambios con bibliotecas soviéticas a las que se envían libros de autores argentinos. "Para realizar su acción, la Asociación solicita el apoyo y la cooperación de los estudiantes, intelectuales y obreros del país que vean con simpatía la obra de la Revolución Rusa y quieran contribuir a su mejor conocimiento entre nosotros”.

El proyecto de la revista es ambicioso: tiene un tiraje de 20.000 ejemplares y, a pesar de contar con una tapa impresa a dos colores y un pliego interno en papel ilustración ofreciendo un novísimo servicio de información fotográfica nacional y mundial, el precio es de sólo 20 centavos. Los editores hacen un gran esfuerzo para impulsar su venta en librerías y kioscos, y fundamentalmente a través de suscripciones y de una red nacional de 
“agentes solidarios”, pues sólo vendiendo todo el tiraje pueden recuperarse apenas los costos. Mientras las publicaciones del PC interpelan al obrero comunista, la Revista de Oriente se dirige a un público más amplio, particularmente el de los obreros, estudiantes e intelectuales influidos inicialmente por el anarquismo y atraídos luego por la revolución rusa, y apela a las firmas de antiguos anarquistas o sindicalistas, como José Vidal Mata, Bartolomé Bossio y, nuevamente, Julio R. Barcos. Y si bien campea una adscripción teórica al marxismo, todavía aparecen fuertes signos del estilo libertario, como cuando un redactor anónimo ironizaba acerca de un Congreso de Trabajadores que había convocado la Liga Patriótica, una fuerza patronal de choque, “donde se destacaban los abdómenes de los frailes, las frentes chatas de los militares, la gomina de los niños bien y la pintura de algunas chicas fifí, pero donde no se dieran cita las manos callosas" ("Notas de actualidad”, 3).

El espectro de colaboradores es amplio: de Insurrexit y Cuasimodo provienen González Lanuza, Angel Rosenblat, Alberto Astudillo, Nicolás Olivari, Herminia Brumana y el siempre activo Barcos. Pero se agregan nuevas firmas: entre los artistas plásticos destacan los grabados de José Planas, Beovide y Pompeyo Audivert. Entre los escritores, se alternan las firmas de los de Boedo y los de Florida. Por una parte, colaboran autores como el narrador y poeta realista Álvaro Yunque; Moisés Kantor, autor de una pieza teatral sobre Lenin; César Tiempo, que publica algunos de aquellos célebres poemas firmados con su heterónimo femenino, Clara Beter; el entonces cuentista y periodista Raúl Scalabrini Ortiz, futuro ensayista del ser nacional, que colabora con un relato (“¡Te vas! ¡Te vas!”) en el que un empleado de una compañía exportadora siente, al ver los barcos mercantiles que zarpan, un llamado profundo a dejar su trabajo rutinario, zarpar con ellos a conocer el mundo y vivir la vida... Por otra parte, aparecen nombres de la vanguardia, como el poeta y ensayista que provenía de la vertiente espiritualista de la reforma universitaria Alfredo Brandán Caraffa, editor de Inicial y de Proa; el poeta ultraísta Jacobo Fijman, que aporta un poema ("Sub-drama”) que gira en torno a las palabras-símbolos que dan el nombre a la revista (“...Orientes y Occidentes/ se quebrarán mis ejes/ Lo sé”) (2: 10) o el activo González Lanuzza, a quien sin duda se debe el comentario sin firma sobre Inquisiciones, en el que el elogio de Borges (nadie como él "ha enardecido la metáfora"; "es el mejor de los escritores jóvenes, así por su cultura como por sus ingénitas cualidades de comprensión y sensibilidad”) (3: 27) se contrapesa con la referencia a "esa milicia indisciplinada y vana que se llama 'nueva generación'”, dentro de la cual “Borges ocupa el lugar de las excepciones” (27). Revista de Oriente debe ser la última revista de izquierda (al menos por muchas décadas) en donde se hace el elogio de Borges, aún a pesar de los devaneos de la "nueva sensibilidad".

En suma, revista de transición hacia las publicaciones culturales comunistas de los treinta -Actualidad, Nueva revista, etc.-, todavía caben y se articulan a su modo vanguardia política y vanguardia artística, marxismo y anarquismo, clasismo y antiimperialismo. Por un lado se mira a la Rusia Soviética, por otro a los intelectuales del Grupo Clarté de París, por otro a Latinoamérica. ${ }^{4}$ Un suelto repetido en números

\footnotetext{
${ }^{4}$ En relación a este último punto, es de destacar la presencia permanente de los apristas: tanto Haya de la Torre y José Carlos Mariátegui, como los peruanos exiliados en la Argentina, enviarán colaboraciones regulares.
} 
sucesivos, "Lo que todos deben leer", da idea de la mezcla: Kropotkine, Bernard Shaw, el libro Prismas, de González Lanuza, La calle de la tarde de Norah Lange, Cerca de los hombres de Francisco Piñero. Pero aparece ya la impronta de la política oficial soviética hacia el arte y la cultura, que irá ganando terreno. Siguiendo a la crítica soviética, Revista de Oriente denosta a Chagall y su exposición de París, comienza a hacer del realismo un canon estético, y si valora las vanguardias rusas, lo hace en tanto se "enderezan" hacia los obreros o colaboran con el gobierno bolchevique. Signos todos de lo que será, desde fines de los veinte, la política comunista oficial durante décadas, a la que irán a subordinarse, en mayor o menos grado, los sucesivos emprendimientos revisteriles del sector, acaso con la única salvedad de Contra, capitaneada en los treinta por Raúl González Tuñón. No es casual que durante la más grande impugnación de esa política cultural, en los intensos años sesenta, una de las revistas emblemáticas de la nueva izquierda, La rosa blindada, escoja a Tuñón como padrino intelectual.

II

BABEL Y LA VIDA LITERARIA: AMERICANISMO, ANTIIMPERIALISMO, SOCIALISMO

Una verdadera red de intercambios unía en los años veinte todos los puntos de América Latina, en un grado que sorprende incluso hoy, en los tiempos de internet. Circulación a través de las revistas (por intercambios entre ellas para su venta, por los canjes de avisos, por los comentarios recíprocos), y circulación de las personas (a través de la nutrida correspondencia, o de los viajes para dictar conferencias, para asistir a congresos políticos, los exilios, etc.). Son los años de la proyección latinoamericana de la Reforma Universitaria, de la Unión Latinoamericana, del primer APRA, de la Internacional Comunista y de los movimientos literarios de vanguardia: todos esos procesos van a propiciar la circulación de ideas, de revistas, de figuras.

Dentro del abigarrado cuadro de vínculos políticos y culturales que se establecen entre distintos puntos de Latinoamérica a lo largo de los años veinte, sobresale la encrucijada que resulta del cruce de tres líneas significativas de pensamiento y acción: el americanismo, el antimperialismo y el socialismo. Cruce de tres líneas que remite a tres figuras claves de la época: el peruano José Carlos Mariátegui, el americano Waldo Frank y el argentino Samuel Glusberg. Un seguimiento de las revistas que animaron, de los textos que unos escribían acerca de los otros y de la correspondencia mantenida entre ellos, permitirá echar luz sobre algunas zonas poco conocidas del campo intelectual y político, tanto en Argentina como en Latinoamérica.

MARiÁtegui descubre a Lenin

Para comprender el peculiar marxismo de José Carlos Mariátegui (1894-1930) es necesario pensarlo como el singular encuentro entre las tradiciones historicistas, activistas y voluntaristas del marxismo europeo, por un lado, con la tradición socialista antiimperialista propiamente latinoamericana, por otro. De un lado, Sorel, Gobetti, Gramsci, pero también Lenin y Trotsky; del otro, la Reforma Universitaria, Ugarte, Ingenieros, Palacios, el primer 
Haya de la Torre. Él mismo ha señalado frecuentemente las estaciones de su itinerario: el periodismo, el vanguardismo literario, la guerra y la revolución, la reforma universitaria, el socialismo, el encuentro con el marxismo en Europa, el retorno a Lima en 1923, el breve encuentro con el aprismo, el accidente y la amputación de las piernas, las conferencias de las que va a resultar La escena contemporánea (1925), el estudio de la realidad peruana “conforme el método marxista”, el proyecto Amauta en 1926. Podríamos agregarle las estaciones siguientes: los Siete ensayos de interpretación de la realidad peruana (1928), la ruptura con el APRA y la fundación del Partido Socialista del Perú (1928), la ruptura con el Komintern (1929), el proyecto de instalación en Buenos Aires, interrumpido por su muerte en abril de 1930.

¿Cómo se cruzan estas estaciones con las propias estaciones del campo intelectual y el campo político argentinos? Dejemos para después las complejidades del campo político (socialismo, comunismo, aprismo) y sus, a su vez, complejas imbricaciones con el campo intelectual. En cuanto a éste, comencemos por señalar que cada uno de estos hitos europeos o latinoamericanos provocaba otras tantas recomposiciones de un campo intelectual sumamente politizado y movilizado, en plena efervescencia y cuyos enlaces latinoamericanos eran numerosos y significativos. Esta proyección latinoamericana de la política y el pensamiento puede parecer extraña al lector de estos días, pero lo cierto es que en los años veinte formaba parte del imaginario colectivo de los intelectuales y políticos latinoamericanos, y se materializaba en un sinnúmero de vínculos.

No es casual, pues, que en esta red viva de vínculos entre Perú y Argentina, Mariátegui fuera un atento lector de Carlos O. Bunge y de José Ingenieros, de Leopoldo Lugones y de Oliverio Girondo, de la generación de los reformistas, de la Revista de Filosofía (1915-1929) de Ingenieros y de Aníbal Ponce, y de la Martín Fierro (19241927) de Evar Méndez. De todos ellos da cuenta en sus artículos periodísticos o en sus ensayos. Mariátegui mismo envía por correo sus ejemplares dedicados de La escena contemporánea y Siete ensayos de interpretación de la realidad peruana a un sinnúmero de escritores argentinos. De un ejemplar del primero de esos libros extrae Aníbal Ponce una serie de ensayos que va publicando en la Revista de Filosofía. Otras revistas argentinas, también de proyección latinoamericana, recogen artículos de Mariátegui - como ya vimos a propósito de la Revista de Oriente- y establecen intercambio de ejemplares con Amauta: Claridad de Buenos Aires, Sagitario (1925-27) y Valoraciones (1924-28) de La Plata. Amauta llegó a la Argentina a través de este aceitado sistema de canjes, por medio de suscripciones (lo que se desprende de la correspondencia de Mariátegui) y, para su venta directa, a través de la librería Samet de Buenos Aires. En 1926 Lugones descubría a Mariátegui en las páginas de la Revista de Filosofía, y se lo hacía conocer a su editor y amigo Samuel Glusberg.

Glusberg descubre a Waldo Frank

Pero varios años antes, el mismo Glusberg había descubierto a otro autor, que, a su vez, lo iba a conducir a la pista de Mariátegui: Waldo Frank. Frank (1889-1967) era un narrador y ensayista norteamericano, nacido en New Jersey en el seno de una familia judía acomodada. Su singular combinación de pacifismo activo, comunismo humanista y fe 
americanista llamaron la atención del inquieto Glusberg, en momentos en que Frank comenzaba a expandir su influencia por América, pero cuando aún no había producido su obra más importante ni había alcanzado renombre internacional.

Por esos mismos años, Frank, de viaje por Europa, tiene el impulso de dirigirse a España, y del encuentro con su cultura y con su gente dará a luz Virgin Spain. España no iba a ser sino un eslabón que lo conduciría a América Latina, y ésta, a su vez, le ayudaría a pensar como un todo a América. Frank aprovecha enseguida el encuentro en Madrid con el mexicano Alfonso Reyes para dirigir a través suyo un "Mensaje a la América Latina" que fue ampliamente reproducido en las revistas de todo el subcontinente.

Dos americanistas respondieron el llamado de Frank. El primero es José Carlos Mariátegui desde Lima, quien se va a ocupar repetidas veces de la obra del norteamericano, mostrándose entusiasta con el ideal americanista de Frank. El peruano había saludado su obra inicial, Our America, como "la más original e inteligente interpretación de los Estados Unidos”, e incluso entendió que las del americano convergían con sus propias tesis americanistas: "En uno de mis artículos sobre ibero-americanismo he repudiado la concepción simplista de los que en los Estados Unidos ven sólo una nación manufacturera, materialista y utilitaria. He sostenido la tesis de que el ibero-americanismo no debía desconocer ni subestimar las magníficas fuerzas del idealismo que han operado en la historia yanqui. La levadura de los Estados Unidos han sido sus puritanos, sus judíos, sus místicos” (154). Según puede observarse en la Correspondencia de Mariátegui, Frank se apresuró a escribirle: “No sé cómo agradecerle este homenaje. He leído ya obras de ud. en muchos periódicos; y mi respeto por ud. se vuelve todavía más humilde frente a este amable saludo desde América del Sur" (159).

La otra respuesta, simultánea, al llamamiento de Frank provino de Buenos Aires. Samuel Glusberg (1898-1987) fue un narrador, ensayista y editor que perteneció a la llamada “generación del 24” y se escondía bajo el seudónimo de Enrique Espinoza. Nacido en Kischinev, Rusia, su padre, el rabino Ben Sión Glusberg, emigró con su familia después de los pogroms desatados contra la población judía de la ciudad rusa en 1905. Animado por una pasión febril por conocer y divulgar que lo acompañó toda su vida, editó su primera revista en los años del colegio normal en Lomas de Zamora. Por esos mismos años, un tío que lo estimula en la lectura le hace conocer a Payró y a Gerchunoff, y él descubre, deslumbrado, a Lugones y Quiroga. Se convierte, inmediatamente, en un apasionado cultor del modernismo literario americano. Dispuesto a difundir sus hallazgos literarios, decide lanzar una colección de folletos que llamó Ediciones Selectas América. Cuadernos mensuales de Letras y Ciencias. Los ejemplares se agotaban y era necesario reimprimirlos dos y hasta tres veces. Eran los años de la cultura del folleto barato, de salida periódica, un lejano antecedente del fascículo de los años sesenta y setenta.

A la publicación de los cuadernos siguió la edición de libros: las Ediciones Babel. Glusberg, a los veinte años, se había convertido no sólo en el difusor de los nuevos valores (Conrado Nalé Roxlo, Ezequiel Martínez Estrada, Luis Franco, entre otros), sino también en el editor preferencial de sus maestros. A mediados de los años veinte, había editado más de sesenta títulos, entre ellos Leopoldo Lugones, Horacio Quiroga, Arturo Capdevila, José Pedroni, Alberto Gerchunoff, Benito Lynch, Alfonsina Storni, Roberto Payró, Evar Méndez... Sus libros combinaban un precio de venta muy bajo (entre 1 y 2 pesos de 
entonces) con la pulcritud de la edición: el nombre Babel no sólo remitía a la torre bíblica, sino que Glusberg, no sin humor, lo había convertido en las iniciales de "Biblioteca Argentina de Buenas Ediciones Literarias”.

En 1921 decidió convertir los cuadernos en una revista que acompañase su política editorial y es así que aparece el primer número de Babel. La revista, además de publicar poemas, cuentos y ensayos de los autores citados, propició encuestas (sobre la educación, el arte, etc.), promovió concursos, y dedicó números especiales a los autores preferidos de Glusberg, que volverán una y otra vez en sus ediciones y en sus escritos: Horacio Quiroga, Luis Franco, Heinrich Heine, entre otros.

En lo que hacía a su propia producción literaria, Glusberg prefería mantenerse en un oculto segundo plano, reservándose a sí mismo la figura del difusor, del animador o del propiciador. Con todo, alcanzó cierto reconocimiento con La levita gris (1924), libro en que reunió una serie de “cuentos judíos de ambiente porteño”. Retornó a la narrativa varios años después con otro volumen de cuentos (Ruth y Noemí, 1934) y dos relatos de viaje (Compañeros de viaje, 1937 y Chicos de España, 1938).

No es fácil clasificar a Glusberg y a su formación cultural dentro de los parámetros Florida/Boedo. Su revista y muchos de sus autores están fuera de uno y otro grupo, como Nalé Roxlo (a quien se considera entre los independientes, a pesar de que colaboró en Martín Fierro), Martínez Estrada, Luis Franco, José Pedroni o Arturo Cancela (este último, autor de la hilarante propuesta de fusionar ambos grupos en un tercero: “Floredo”). Y si su propia narrativa lo aproxima más a cierto realismo social -la gran literatura rusa del siglo xix había sido el punto de partida de su formación cultural- y su fervor lugoniano lo alejan de cualquier actitud parricida, en 1924 aparece ligado nada menos que a la fundación de la revista vanguardista Martín Fierro. ${ }^{5}$

Los jóvenes que lo acompañan en la empresa de Babel son el poeta catamarqueño Luis Franco, el poeta y futuro ensayista Ezequiel Martínez Estrada, el humorista Arturo Cancela, así como una "poetisa” que acaba de editar un libro, Languidez, y que este primer número celebra así: "la señorita Storni ha escrito el más bello libro de versos del año pasado”. Los jóvenes han conseguido que la revista sea apadrinada por la generación anterior: Leopoldo Lugones, Roberto Payró, Horacio Quiroga, Ricardo Rojas.

La periodicidad quincenal pasa a ser, después de los primeros números, mensual. Las siguientes entregas mantienen este carácter abierto, un tanto ecléctico, donde caben tanto los poemas paganos de Luis Franco, los versos sencillos de Fernández Moreno y el más que clásico "Romancero” de Don Leopoldo Lugones, del que se van a burlarse agriamente los vanguardistas de Martín Fierro. Consagrados y noveles: por un lado, se publican aquí por primera vez los trípticos morales de José Ingenieros (reunidos después de su muerte en Las fuerzas morales); por otro, el primer avance que hace Roberto Arlt de El juguete rabioso, bajo el título "Recuerdos del adolescente” (11 enero 1922).

\footnotetext{
5 "La idea [de relanzar la revista Martín Fierro] fue de Samuel Glusberg, quien convenció a Evar Méndez” (González Tuñón 15).
} 
AMERICANISMO

En el mismo momento en que se difundía en el subcontinente la carta de Frank, Glusberg editaba La levita gris, y le enviaba a Frank, como respuesta a su llamado, un ejemplar dedicado. "Desde entonces datan mis relaciones directas con el maestro, pues éste no tardó en contestarme. Y a pesar de que su primera carta no llegó a mis manos, volvió a escribirme algún tiempo después, reiterándome sus felicitaciones y su pedido de autorización para traducir dos cuentos del libro para The Menorah Journal de Nueva York. Naturalmente, yo le escribí a mi vez reconocidísimo por todo. ¿Qué más podía esperar un cuentista nobel?” (Espinoza, Trinchera 31).

También aquí comienza un frondoso epistolario y una amistad personal que sólo se iban a interrumpir con la muerte de Frank: intercambios de ideas, estímulos mutuos, proyectos de ediciones aquí y allá, y números. Porque el espiritualista Frank sabía ser muy concreto a la hora de hablar de derechos de autor y honorarios de conferencias. Pero el solícito Glusberg se las arregla siempre para conseguir lo necesario y satisfacer a su amigo Frank. También en la consagración de esta “hermandad” se había operado una identificación -y si Mariátegui habló de Frank como un hermano mayor, y Glusberg en el texto público citado lo llamó “maestro", lo cierto es que el trato más habitual en su correspondencia era el de "hermano”. Jesús Méndez fue el primero en señalar los puntos de identificación entre Frank y Glusberg. En primer lugar, ambos eran judíos, y "se veían a sí mismos como profetas espirituales clamando contra el salvajismo del materialismo americano". Por otra parte, profesaban una suerte de "nacionalismo" americanista: ambos recelaban de la dependencia cultural de América hacia Europa y ponían el énfasis en los valores hemisféricos del Nuevo Mundo (Méndez 5).

Así, invitado Glusberg por la revista Martín Fierro a responder la encuesta sobre la “sensibilidad argentina”, sale al cruce de un artículo de La Gaceta Literaria de Madrid que proclamaba a esa ciudad "el meridiano intelectual de Hispanoamérica”, estampando su profesión de fe americanista, oponiéndose tanto al nacionalismo argentino como al hispanismo. También Mariátegui había salido al cruce de la revista madrileña desde las páginas de Amauta, así como Frank, en Our America, había reaccionado contra el peso de la dominación cultural británica sobre el país del norte.

Es así que de la correspondencia entre Frank y Glusberg, entre intercambios de ideas y de libros, surge el acuerdo de la edición en español del libro Nuestra América por Babel y del viaje de Frank a la Argentina (según consta en la correspondencia inédita en el Archivo Glusberg) ${ }^{6}$. Frank llega a Buenos Aires, finalmente, en setiembre de 1929, pero su amigo Glusberg se adelanta, para esperarlo en el puerto de Montevideo, con el ejemplar de Nuestra América recién salido de la imprenta (Espinoza, 1932; Frank, 1975).

\footnotetext{
${ }^{6}$ N. del E. La correspondencia entre Frank y Glusberg, así como de éste con Mariátegui fue editada por el autor de este artículo, con posterioridad a la redacción del mismo (Tarcus, 2002). Las cartas se citan siguiendo la fuente del Archivo Glusberg, ubicado en el CeDinCi (Buenos Aires).
} 


\section{El triángulo Fran/Mariátegui/Glusberg}

Mientras prepara el viaje de Frank, Glusberg tiene referencias, por Lugones, desde 1926, de la obra de Mariátegui. Además, a fines de ese mismo año, y dentro de esa red latinoamericana, comienza a recibir Amauta. Para mejor, descubre que el peruano también se ha interesado por Frank y le escribe pidiéndole que le envíe el comentario que había escrito a propósito de la aparición de Virgin Spain.

Mariátegui responde con afecto y entusiasmo, y la correspondencia, que se extiende desde entonces (1927) hasta su muerte (1930), se centrará en preocupaciones comunes. Tengamos en cuenta que también aquí se operan una serie de implícitas identificaciones: tanto Glusberg como Mariátegui tienen un origen humilde, son intelectuales autodidactas, animados por un colosal voluntarismo, un poderoso afán de promoción cultural de lo mejor de cada una de sus respectivas culturas. También se hacen visibles las diferencias: mientras Mariátegui es, o quiere ser, un hombre de partido, Glusberg no es, estrictamente, un político: es un intelectual de izquierda, un escritor politizado. Mariátegui, desde Lima, lanza Amauta en 1927, y Glusberg abandona Babel y lanza, desde Buenos Aires, un nuevo proyecto revisteril: La Vida Literaria (1928-1932). La diferencia entre Amauta y La Vida Literaria consiste en que detrás de la primera hay una clara vocación de construcción hegemónica. Sin embargo, el interés de La Vida Literaria excede su lugar de exponente del modernismo literario tardío (Lugones, Quiroga, Storni, Payró): está en el cruce singular entre americanismo, anti-imperialismo y socialismo que intenta articular la formación intelectual que lidera Glusberg, y que quiere proyectar hacia toda América por medio de una asociación triangular con Waldo Frank en los EE.UU. y el Mariátegui de la revista Amauta desde Perú.

Una de las preocupaciones comunes de la correspondencia entre Mariátegui y Glusberg gira en torno al envío recíproco de libros y artículos. Entre los años que se desarrolla este epistolario, Glusberg edita una revista efímera, los Cuadernos de Oriente y Occidente, cuyo $\mathrm{n}^{\circ} 1$ reproduce un trabajo de Mariátegui, y comienza la publicación de La Vida Literaria, que establece una hermandad creciente con Amauta. La revista de Glusberg publica numerosas noticias sobre su par peruana, muchos artículos de Mariátegui y las primeras fotos y noticias biográficas sobre su director aparecidas en nuestro medio. Recíprocamente, en Amauta son comentadas las publicaciones de Glusberg.

Paralelamente, en el transcurso de los años 1927-30, va creciendo el aislamiento político de Mariátegui (ruptura con el APRA, rechazo de sus tesis por el Komintern). Su principal interlocutor y difusor en Buenos Aires, luego encargado de su traslado a esta ciudad, es justamente, Glusberg, un independiente de izquierda. Sin ignorar el compromiso político de Mariátegui, Glusberg no deja de aconsejarle que ingrese al país enfatizando su perfil de escritor antes que su perfil de político (carta del 6 diciembre 1928). Lo previene de los agrupamientos políticos, y le aconseja no llegar asociado a ninguno de ellos. Es que Glusberg se ha responsabilizado de la instalación y de la futura subsistencia de Mariátegui en la Argentina, y el punto para él es ampliar el espectro de solidaridad con el futuro expatriado.

Otro de los frutos del intercambio entre Glusberg y Mariátegui es la visita de Frank al Perú. Como vimos, ya existía un acercamiento epistolar entre Frank y Mariátegui, pero 
es Glusberg, mientras prepara el viaje del americano a la Argentina, quien le ofrece programar una escala de la gira en Perú: “¿No cree ud. en la posibilidad de hacerle llegar a Frank una oferta universitaria para que visite también el Perú?” (28 enero 1928). Mariátegui se entusiasma, y se compromete a gestionar la invitación a Frank: "En la Facultad de Letras no faltan catedráticos amigos”, especialmente después de la Reforma (4 julio 1928). Y asume el esfuerzo de organización de la visita. Frank, al tanto del acuerdo, le escribe anunciándole su llegada a Lima para diciembre y se ilusiona con el encuentro: "Ya puedo figurarme las horas que charlaremos y discutiremos juntos, usted y yo! Como tenemos mucho que decir! Principalmente como tengo yo mucho á aprender de ud.” (sic. 21 abril 1929). En una carta referida al eco que encontró Frank en Lima (18 diciembre 1929), Mariátegui le confiesa a Glusberg que el amigo americano lo había “afirmado en mi intención de marchar a Buenos Aires. La invitación de un amigo y compañero como Usted coincide con las circunstancias que le describe mi penúltima carta [en alusión a su última detención]. El contacto con un país sano y fuerte me hará mucho bien, espiritual y físicamente. En Buenos Aires terminará mi convalecencia que la debilidad de Lima ha retardado”. Tras su primera detención, en junio de 1927, acusado de formar parte de un “complot comunista”, Mariátegui le escribía a Glusberg (30 setiembre 1927) agradeciéndole el telegrama de los escritores argentinos a Leguía reclamando su libertad (Glusberg había conseguido reunir inmediatamente firmas de figuras como Payró, Lugones, Quiroga y Gerchunoff) y es en esta carta que aparece la primera expresión de deseos de abandonar el Perú e instalarse en la Argentina: "Trataré de reanudar en Lima la publicación de Amauta. Si no pudiera conseguir la reconsideración de su clausura, me dedicaré a preparar mi viaje a Buenos Aires para establecer ahí la revista...”.

Glusberg, siempre solícito, le responde: “¿Y cuándo sale Amauta? ¿O se viene ud. a Buenos Aires? Avíseme a tiempo y cuente conmigo para todo lo que pueda ser de utilidad” (diciembre 1927). El 10 de enero del año siguiente Mariátegui le anuncia la reaparición de Amauta, advirtiéndole que vendría a Buenos Aires ante cualquier nuevo problema. Glusberg le insiste sobre su viaje a la Argentina y compromete a Frank en el asunto: "Waldo le hablará de mis propósitos de patrocinar por intermedio de La Vida Literaria su visita a la Argentina. Dígame cuánto dinero necesita para salir de Lima y lanzaré la iniciativa. Creo que no me será difícil conseguirlo” (19 noviembre 1929). Como vimos, Frank promovió el traslado, acariciando el proyecto una gran revista continental con sede en Buenos Aires que contuviera a los tres.

La invitación de Glusberg no podía ser más propicia: el 18 de noviembre de 1929, días antes de la llegada de Frank al Perú, se produce la segunda detención de Mariátegui. Tras ser liberado, le escribe inmediatamente a Glusberg (21 noviembre 1929): “Mi propósito de salir del Perú con mujer y mis niños se afirma ante estos hechos" (Correspondencia 673). Y una semana después (21 noviembre 1929): “dispondré de más tiempo y calma para preparar mi viaje a Buenos Aires [...] No me es posible trabajar rodeado de acechanzas” (686). Glusberg (28 diciembre 1929) le traza un cuadro de la situación económica en Buenos Aires, le cuenta cómo va propiciando el “clima Mariátegui” desde La Vida Literaria y le anuncia el envío a fines de marzo o principios de abril del dinero de los pasajes para toda la familia (“¿Cuántos hijos tiene?”). Además, le anuncia un especial de La Vida Literaria dedicado al Perú con motivo de su arribo y la organización de un festival en su homenaje para recaudar fondos. 
Mariátegui prepara su viaje sin imaginar que son esos sus últimos días. Anota Glusberg: “Mientras me preparaba para recibir a José Carlos Mariátegui fraternalmente, como a un genuino embajador espiritual del Perú, mientras él mismo, lleno de fe en su tan soñado viaje a Buenos Aires, empezaba a remitirme, como credenciales, las primeras colaboraciones de aquellos a quienes representaría entre nosotros: he aquí que su muerte, torciendo su itinerario porteño, nos lo aleja para siempre. Y así, este número de La Vida Literaria, que debía ser de acercamiento, como aquel otro norteamericano, con motivo de la visita de Waldo Frank, sale, por el contrario, como un número de despedida” (Espinoza, La Trinchera 40).

Y Frank, a su vez, anotó en sus Memorias: "Yo trabajaba, dichoso, en mi libro Virgin America. Trabajaba jubilosamente. El viaje había sido de buen augurio. Entonces llegó la noticia de la caída de Yrigoyen... y de la muerte de Mariátegui. Lloré...” (284).

El imposible triángulo entre Frank, Glusber y Victoria

Pero volvamos tan sólo unos meses atrás. Recordemos que Glusberg viene promocionando la gira de Frank desde La Vida Literaria. Frank llegó finalmente a Buenos Aires en setiembre de 1929 y es entonces cuando discute con Glusberg el plan de editar una revista literaria argentina de proyección continental y perspectiva americanista, que se llamaría Nuestra América.

Pero las cosas se complicaron, en parte como resultado del propio éxito de Frank en la Argentina. Todas las instituciones culturales, desde la aristocrática Amigos del Arte hasta la recién creada Sociedad Argentina de Escritores, lo recibieron y lo homenajearon. Sus conferencias se convirtieron enseguida en un suceso nacional y Frank lució en la primera plana de los diarios argentinos. "En Buenos Aires -reconoció en sus Memorias-, monté una especie de teatro intelectual” (276).

Fue al final de una de sus conferencias en los Amigos del Arte que conoció a Victoria Ocampo, una de las mayores exponentes de la élite literaria. De su común deslumbramiento hablan las Memorias de Frank y los Testimonios de la Ocampo. Es en este contexto de recíproco encantamiento que Frank tuvo la desdichada idea de incluir a Victoria en su proyecto de revista común con Glusberg y Mariátegui. Recuerda en sus Memorias: “Con esa intención la puse en contacto con Samuel Glusberg (ellos no se conocían). Sus variedades de cultura se enriquecerían recíprocamente y enriquecerían al órgano del Nuevo Mundo que entraba en mis proyectos. El aporte de Victoria sería la familiaridad con los clásicos y con las últimas novedades de París y Londres en el campo de las artes y las letras; el aporte de Glusberg sería su sólido conocimiento de los problemas sociales y de la visión profética de las Américas” (282). Frank partió de Buenos Aires convencido de haber propiciado una verdadera fundación, y le escribía a Glusberg desde su escala en Lima refiriéndose a Mariátegui, Victoria y el propio Glusberg: “Si ayudo yo a juntar á vosotros tres en una obra continental, no seré yo sin valor en la historia de América hispana” (sic, Lima, 6 diciembre (1929), Archivo Glusberg).

Pero la alquimia intentada por Frank perdió su efecto apenas se alejó el propiciador. Victoria y Glusberg, la dama aristocrática y el inquieto inmigrante, no iban a entenderse. A los desencuentros en la discusión del proyecto, se sumó la negativa de Victoria a 
colaborar económicamente en el viaje de Mariátegui. El propio Frank venía solicitándole infructuosamente su ayuda económica.

Victoria, en su relato del nacimiento de la revista, omitiendo por completo cualquier mención a Mariátegui, a Glusberg y al acuerdo inicial entre éste y Frank, narra su encuentro con el norteamericano en Nueva York para retomar las conversaciones iniciadas unos meses atrás en Buenos Aires. Según se desprende de las cartas de Frank a Glusberg, aquél intenta convencer en vano a Victoria de los valores intelectuales de su amigo (Cartas del 15-7, 5-9, 30-10 y 30-12 de 1930, Archivo Glusberg).

Por su parte, Glusberg se anticipa a anunciar en la portada de La Vida Literaria: "Victoria Ocampo dirigirá una gran revista americana”. A pesar de las formas corteses de la nota que firma con su heterónimo Enrique Espinoza, no es difícil adivinar que Glusberg busca meter en aprietos a Victoria. Por ejemplo, consciente del padrinazgo que sobre ella ejercía Ortega y Gasset y del deslumbramiento de la Ocampo por las letras francesas, Glusberg busca contraponer la necesidad de una revista americana a la cultura europeísta que representan la Nouvelle Revue Française o la Revista de Occidente. Inclusive se permite deslizar una sutil ironía sobre la orientación genuinamente americanista de la nueva revista: “¿Cómo se llamará la revista representativa de ese gran organismo nacional y americano que acaba de proyectar Victoria Ocampo con Waldo Frank en Nueva York? ¿Nuestra América, acaso? Es lo que haremos saber a nuestros lectores en un próximo reportaje a Victoria Ocampo” (1) (julio 22 1930).

En agosto, Victoria le escribe a Frank informándole de los potenciales problemas con los jóvenes escritores vanguardistas que traería la asociación con Glusberg. Por su parte, Glusberg desconfiaba de los vínculos ideológicos de los escritores vanguardistas cosmopolitas con la élite oligárquica, y de los “jóvenes tipo Borges y otros, que no tenían siquiera el coraje de ser abiertamente reaccionarios y católicos” (Méndez 10).

Victoria terminaría apropiándose íntegramente del proyecto de la revista, que finalmente fue bautizada, a sugerencia de Ortega, Sur. El viejo proyecto cooperativo había devenido su empresa privada. El primer número aparecería en enero de 1931 y Glusberg no tardaría en comentarlo en el nº 28 (1931) de La Vida Literaria, con sentido crítico pero con ponderado equilibrio: es, dice Espinoza de la nueva revista, "tan buena como sus colegas similares de París”, y agrega: "como cualquiera de estas revistas europeas Sur merece nuestro elogio leal; pero no como revista argentina y menos americana” "“Sur. Revista trimestral de V. Ocampo" 3). Y si elogia su calidad y su factura, le reprocha su "falta de sentido". Y aclara: “sentido propio, americano" (3). Esta es quizás, en forma matizada, la primera crítica al “europeísmo” de Sur que, en formas más agresivas, hará fortuna en la crítica cultural argentina de los años cincuenta y sesenta.

Frank acompañó, por un lado, la trayectoria de Sur y, por otro, mantuvo su amistad epistolar con Glusberg. No sin reconocer ciertos valores en el proyecto Sur, nunca dejó de lamentar el fracaso del proyecto inicial: "Victoria fundó Sur, y ésta se convirtió en un respetable testimonio de cultura. Pero Glusberg, el dinámico inmigrante judío que llevaba en su corazón la América profética, y Victoria Ocampo, la princesa del buen gusto, se separaron tan pronto como se conocieron. Mi alianza cultural no pasó de ser un sueño” (Memorias 282). 
Estas palabras de Frank, que aparecieron en la edición póstuma de sus Memorias, venían a enturbiar la "historia oficial” de la fundación de Sur instituida por Victoria. Esta indiscreción de su viejo amigo la obligó a romper un silencio de casi medio siglo y en uno de sus Testimonios (1975) reacciona frente a aquel tramo sobre "el inmigrante judío que llevaba la América profética en el corazón”: “¡Epa! -se indigna Victoria-Yo también tenía una América en el mío” (39). Pero la confesión de Frank, así como el hallazgo de las cartas de Glusberg en Pennsylvania (Méndez 3-16) y las de Frank en Buenos Aires (Archivo Glusberg), han venido a mostrar una génesis un poco más compleja de la gestación de Sur que la establecida por la versión oficial.

Está claro que entre Victoria y Glusberg pesó más el corte de clase que la común pertenencia a una comunidad intelectual. Eran abismales las diferencias dictadas por sus orígenes sociales, sus estilos de vida, sus ideologías. Pero, por otra parte, ¿qué era lo que había fallado en la hermandad americanista de Frank y Glusberg? ¿Qué es lo que motivó todo el malentendido que, de Nuestra América, condujo a Sur? Si ya hablamos de los puntos de identificación entre Frank y Glusberg, se hace necesario señalar aquí sus puntos de contraste: entre los modestos orígenes sociales del inmigrante ruso y la familia acomodada del americano, entre el autodidacta de Buenos Aires y el egresado sobresaliente de la Universidad de Yale, entre la figura desgarbada del oscuro editor del barrio porteño de Barracas y la figura esbelta del niño rebelde de Greenwich Village que sedujo a Victoria.

La muerte de Mariátegui y el frustrado proyecto con Frank desalentaron a Glusberg, que dejó de editar La Vida Literaria en 1932. Los treinta, años de crisis, más los sinsabores, los desencuentros y, acaso, la amistad epistolar con Mariátegui, politizaron más a Glusberg. En 1932 publicó su primer libro de ensayos, Trinchera, en el que -bajo su seudónimo Enrique Espinoza- resume lo que podríamos llamar su política cultural. Pero, tras la muerte de Mariátegui y la partida de Frank, Glusberg es un hombre solo. Escribe: "Waldo Frank nos llegó a dar cierta cohesión en torno a su persona, durante las siete semanas que estuvo con nosotros. Pero a su partida, el núcleo se deshizo rápidamente. Luego, la muerte de José Carlos Mariátegui malogró nuestra iniciativa de una gran revista continental en Buenos Aires” (7).

Glusberg, pues, no se identifica con el rumbo que ha tomado su maestro Lugones, pero tampoco con el de su propia generación, que adoptó - afirma-primero una orientación radical y, tras apoyar el golpe de 1930, devino conservadoramente apolítica. La alusión al itinerario de Jorge Luis Borges es aquí evidente. Desalentado del curso político y cultural que toma el país, se instala imprevistamente en Chile en 1935. R. Borello ha inscripto su voluntad de autoexilio en el clima pesimista del período: "La experiencia que vive el país hacia 1930, en la que a la crisis económica se suma el golpe de Estado y el derrumbe de los ideales del liberalismo burgués, se reflejará también en la situación y prestigio de la literatura y sus autores. Esos hechos producen un desconcierto generalizado en las capas cultas de la clase media y en los escritores y críticos nacidos de ella. La desaparición del optimismo anterior dará lugar a un impreciso proceso que, moldeado sobre la pérdida de libertad popular que había vivido el país hasta ese momento, originará la desconfianza hacia el intelectual y un clima opresivamente difícil para el escritor y las tareas intelectuales. Es a partir de esos años cuando se suicidan numerosos escritores 
argentinos (Lugones, Quiroga, A. Storni, E. Méndez Calzada, Enrique Loncán, Edmundo Montagne); otros callan para siempre, como Banchs; alguno se destierra voluntariamente (Samuel Glusberg)...” (1062-63).

Los treinta, en efecto, con su aguda crisis económica, social e institucional, y con su característica convulsión intelectual, empujarán a la radicalización política a Glusberg y a Frank, aunque cada uno a su modo: el primero se radicalizará hacia Trotsky, el segundo hacia el partido comunista de los Estados Unidos. Glusberg, afincado en Santiago, no tardará en reunir un cenáculo con el que relanzar su revista. Su grupo íntimo se irá conformando con el narrador Manuel Rojas, el crítico chileno Hernán Díaz Arrieta (Alone), el humorista J.S. González Vera, el ensayista libertario chileno Laín Diez; el escritor y periodista chileno, residente en los EE.UU., Ernesto Montenegro y el diseñador, Mauricio Amster, un vanguardista polaco que venía de revolucionar el diseño gráfico en la España republicana. Con su ayuda, y con las colaboraciones regulares que desde Argentina envían Martínez Estrada y Luis Franco, relanza Babel, que se editará entre 1940 y 1951. Esta nueva etapa señalaba un corte claro con las revistas que editaba en la Argentina. Estas estaban abiertas a un amplio abanico ideológico que en la Babel chilena se cerrará por izquierda. La consolidación del stalinismo en la Unión Soviética, por una parte, y el estallido de la revolución y la guerra españolas, por otro, van a marcar otro corte decisivo que recompondrá nuevamente el campo intelectual y el campo político latinoamericanos. Sur, después de cierta confusión inicial, se orientará hacia un liberalismo conservador, antifascista y anticomunista. Babel, desde Santiago, será un vocero del pensamiento socialista libertario. Conmocionado por los dichos acontecimientos mundiales, Glusberg buscó un acercamiento a Trotsky y a la oposición de izquierda internacional, siempre más interesado en la dimensión ético-política del mensaje trotskista que en su propuesta organizacional. Es así que Babel va a abrir sus páginas a autores como el propio Trotsky, al poumista español Juan Andrade, al anarco-trotskista Víctor Serge, al líder trotskista americano James P. Cannon, así como a otros escritores que rompían con el comunismo sin dejar de reivindicarse por entonces como izquierdistas, como Jean-Paul Sartre, Paul Mattick, Ignacio Silone, André Gide, Arthur Koestler, Sidney Hook, Bertram Wolfe, André Malraux, Arthur Rosenberg, Albert Camus, Dwight Mac Donald o Edmund Wilson... Residió en Chile hasta 1973, año el año del golpe militar encabezado por el Gral. Pinochet, regresando a la Argentina, donde murió en 1987.

Bibliografía

Manuscritos y fuente inéditas

Archivo Glusberg. Buenos Aires. CeDInCI (Centro de Documentación e Investigación de la Cultura de Izquierdas en la Argentina).

Fondo Mika Etchebehre. Buenos Aires. CeDInCI(Centro de Documentación e Investigación de la Cultura de Izquierdas en la Argentina).

Revistas citadas

Insurrexit. Revista Universitaria 1 (Buenos Aires, setiembre 1920).

Insurrexit. Revista Universitaria 12 (Buenos Aires, noviembre 1921). 
Cuasimodo. Revista Decenal. (primera época: Panamá, $n^{\circ} 1$ al 13: 1920; 2ª́poca: Buenos Aires, $n^{\circ}$ 14: abril 1921; $n^{\circ}$ 27: dic. 1921). Dir.: Nemesio Canale/Julio R. Barcos; luego sólo éste último; en el n 23 aparece como director F. Olea; a partir del n 25 , Julio R. Barcos/Rómulo Schenini.

Prisma. Revista Mural. Buenos Aires ( $n^{\circ} 1$ : dic. 1921-n² 2: marzo 1922). Dir.: Eduardo González Lanuza.

Revista de Oriente [órgano de la Asociación amigos de Rusia]. Buenos Aires ( $n^{\circ} 1$ : jun. 1925- no 9/10: set. 1926).

Babel. Revista de Arte y crítica. Buenos Aires (primera época: $n^{\circ} 1$ : abr. 1921- n 31: 1928; $2^{a}$ época: Santiago de Chile, $n^{\circ} 1: 1939-n^{\circ}$ 60: 1951). Dir.: Enrique Espinoza [Samuel Glusberg].

La Vida Literaria. Crítica, información, bibliografía. Buenos Aires (nº 1: jul. 1928-nº 43: jul. 1932). Dir.: Enrique Espinoza [Samuel Glusberg].

AA.VV. "El periódico Martín Fierro. Memoria de sus antiguos directores". Buenos Aires: s/e, 1949 (redactada por Oliverio Girondo y aprobada por los otros directores: Evar Méndez, Alberto Prebisch, Eduardo J. Bulrich).

Ayerza de Castillo, Laura y Odile Felgine. Victoria Ocampo. Barcelona: Circe, 1993.

Barcos, Julio R. “Entre los míos”. Cuasimodo (abril 1921): 10-11.

Borello, Rodolfo. “La crítica moderna”. Capítulo. La historia de la literatura argentina 45 (Buenos Aires: CEAL, 1967).

Borges, Jorge Luis. "Rusia”; “Guardia roja”. Cuasimodo. Revista decenal 27 (1921). "Las memorias de...”. La Opinión. Segunda sección (17 set. 1974).

, Alberto Hidalgo y Vicente Huidobro. Índice de la nueva poesía americana. Buenos Aires: El Inca, 1926.

Textos recobrados (1919-1929). Buenos Aires: Emecé, 1997.

Córdova Iturburu, Cayetano. La revolución martinfierrista. Buenos Aires: ECA, 1962.

Ciria, A y H. Sanguinetti. Los reformistas. Buenos Aires: Jorge Alvarez, 1968.

Doeswijk, Andreas. Entre camaleones y cristalizados: los anarco-bolcheviques rioplatenses. 1917-1930. Tesis de doctorado. Campinas: UNICAMP, 1998. (s/n)

Espinoza, Enrique (Samuel Glusberg). La noria. Buenos Aires: Losada, 1962. Trinchera. Buenos Aires: Babel, 1932.

Etchebehere, Mika. “Hipólito Etchebehere”, texto mecanografiado de una carta a un corresponsal argentino no identificado, s/f [c. 1973]. Fondo Mika Etchebehere del CeDinCi. Buenos Aires.

Frank, Waldo. Memorias. Buenos Aires: Sur, 1975.

González Tuñón, Raúl. “Crónica de Florida y Boedo”. La literatura resplandeciente. Buenos Aires: Boedo/Silbalba, 1976.

King, John. Sur. Estudio de la revista argentina y de su papel en el desarrollo de una cultura. 1931-1970. México: FCE, 1990.

Lafleur, H.R., Sergio Provenzano y Fernando Alonso. Las revistas literarias argentinas. 1893-1967. Buenos Aires: CEAL, 1968.

“La Universidad”. Editorial. Insurrexit 7 (marzo 1921): 1

Maitron, Jean, dir. Dictionnaire biographique du mouvement ouvrier français. Paris: Editions Ouvrieres, 1997. (Edición digital), voces "Etchebéhère, Hippolyte” y “Etchébehère, Mika”, redactadas por M. Bonnel y M. Dreyfuss. 
Mariátegui, José Carlos. "El alma matinal y otras estaciones del hombre de hoy”. Obras Completas. Vol. 3. Lima: Amauta, 1959. Correspondencia. Lima: Amauta, 1984.

Méndez, Jesús. “The Origins of Sur. Argentine’s Elite Cultural Review”. Revista Interamericana de Bibliografía XXXI/1 (1981).

"Notas de actualidad”. Revista de Oriente 1/1 (1925): 3.

Ocampo, Victoria."Vida de la revista Sur. 35 años de una labor”. Sur n 3-3-304-305 (noviembre 1966-abril 1967).

Testimonios. Novena serie. Buenos Aires: Sur, 1975.

Testimonios. Décima serie. Buenos Aires: Sur, 1979.

“Correspondencia”. Sur 347 (jul.-dic. 1980).

“Victoria Ocampo. 1890-1979. Homenaje”. Sur 346 (ene.-jun. 1980).

Pereyra, Washington. La prensa literaria argentina. Tomo segundo: Los años rebeldes 1920-1929. Buenos Aires: Librería Colonial, 1995.

Piñero, Francisco M., Cerca de los hombres. Buenos Aires: Tor, 1923.

Prieto, Adolfo. "Boedo y Florida”. Estudios de literatura argentina. Buenos Aires: Galerna, 1969.

Ricard, F. “Voces amigas”. Cuasimodo (abril 1921): 24.

Rodríguez, Fernando, D. “Inicial. Revista de la nueva generación. La política de la vanguardia literaria de los años '20”. Estudios Sociales V/8 (Santa Fe, 1995).

"Inicial, Sagitario y Valoraciones. Entre las letras y la política. Juvenilismo y americanismo en la década del '20”, mimeo, 1997.

Sarlo, Beatriz. "Vanguardia y criollismo: la aventura de Martín Fierro”. Ensayos argentinos. De Sarmiento a la vanguardia. Beatriz Sarlo y C. Altamirano, eds. Buenos Aires: CEAL, 1983.

Una modernidad periférica: Buenos Aires 1920 y 1930. Buenos Aires: Nueva Visión, 1988.

Tarcus, Horacio, Mariátegui en la Argentina, o las políticas culturales de Samuel Glusberg. Buenos Aires: El Cielo por Asalto, 2002.

“Samuel Glusberg, entre Mariátegui y Trotsky”. El Rodaballo 4 (1996) y 5 (1996/ 97). Reproducido en el Boletín Amauta y su época, 3 y 4, Lima (1997).

"El pensamiento latinoamericano en los '20: americanismo, antiimperialismo, socialismo”. La cultura en la Argentina de fin de siglo. M. Margulis y M. Urresti, eds. Buenos Aires: Oficina de Publicaciones del CBC, 1997.

“Babel”. Lote (Venado Tuerto, noviembre 1997).

“Amauta en Buenos Aires (o las redes del pensamiento latinoamericano en los '20:

americanismo, antiimperialismo y socialismo)”. AAVV, Amauta y su época. Lima: Miraflores, 1998.

Terán, Oscar, “Modernos intensos en los veintes”. Prismas. Revista de historia intelectual. Universidad de Quilmes, 1(1997).

Viñas, David, dir. / Graciela Montaldo, ed. Historia social de la literatura argentina. Tomo VII: Yrigoyen, entre Borges y Arlt (1916-1930). Buenos Aires: Contrapunto, 1989. 